\title{
THE IMPORTANCE OF THE GEONOMIC DIMENSIONS FOR GEODYNAMIC CONCEPTS
}

R. W. VAN BEMMELEN

Geological Institute, State University, Utrecht (The Netherlands)

SUMMARY

An analysis is made of the importance and interrelation of the parameters of length, time, pressure and temperature, and their bearing upon concepts regarding the earth's evolution. This leads to a tentative model of the chain of reactions caused by the continuous escape of the endogenic energy from the earth's interior.

\section{INTRODUCTION}

For an insight into the position of the earth sciences or "geonomy" within the great spectrum of the natural sciences, it is necessary to realize the relative importance of the parameters involved in the earth's evolution.

In the following pages the author discusses first the linear size of the objects of scientific study and the parameter of length between some of these entities of observation (see the following section, Table I). Then the parameter of time in relation to length is considered (Table II). This gives us an insight into the mean velocities involved in the processes of global evolution. A third diagram (Table III) illustrates the proposed model of the structural levels or "Stockwerke", according to the results from contemporary research. Finally, in the final section an attempt is made to outline the chains of reactions that are caused by the endogenic energy during its course outward, from core to surface.

In this concept of chain-reactions the author attempts to take into account all major aspects of our knowledge of the earth and to weigh their relative importance. It repudiates, cutting haphazardly through the Gordian knot of antinomies which exist in present-day geonomy. The author arrives at a relativistic synthesis, into which the current static (fixistic) and dynamic (mobilistic) models are united, and in which their controversies can be bridged. 
THE PARAMETER OF LENGTH IN GEONOMY

In Table I the linear size and the mutual distances of the objects of study in the natural sciences are illustrated. Its logarithmic scale bridges the dimensions in length from smaller than $10^{-13} \mathrm{~cm}$ to greater than $10^{27} \mathrm{~cm}$.

At the lower end of the diagram beyond one Fermi $\left(10^{-13} \mathrm{~cm}\right)$, no means of scientific observation are available. There one descends into the domain of speculations pertaining to philosophy. However, it is as yet impossible to check these speculations by means of sensorial or instrumental observations. Similarly, at the upper end of the diagram (beyond the farthest quasi stellar objects- Quasars) at distances up to $15 \cdot 10^{9}$ light years, only just discernable by means of telescopes, our present means of investigation fail. One might speculate on the existence of other worlds of matter and antimatter with immense battles of annihilation in their frontal zones, but we have no means to verify the truth value, the functional adequacy of such mental models: there we leave the domain of verifiable science.

It is clear that Man is limited in his study of Nature by his restricted capacities of observation, however clever are the instrumental aids which he has devised. The spectrum of the sciences of Nature is embedded between two realms, into which he might be admitted only by means of ultra-sensorial faculties of intuition, inspiration or revelation. This is the mystical world of spiritual unity, which is indicated by the concept of religion, but it ceases to be a natural science.

These ultimate limits of natural science can be characterized by the famous words of Alexander Pope: "Fools rush in, where angles fear to tread". In this review paper we should restrict ourselves to the central interval of the gamut, i.e., to the "octave" of geosciences or "geonomy", which lies embedded between the octave of basic sciences in the lower part and that of astronomy in the upper part.

Between these two ultimate ends of our world of natural science as delimitated by speculative philosophy stretches the entire domain of human material experience of the early-day concept of "matter". Between these ultimate philosophical boundaries of this scale of natural science and the classical concept of our material world present-day science we encounter transitional fields of matter. At the upper side are the Quasars, which tumble over the Einstein limits of our universe. At the lower side matter is reduced to mere quanta of energy.

In the lower part of this spectrum of the natural sciences our observations penetrate into the sub-microscopic domain, where the phenomena and processes are still governed by electro-magnetic and Van der Waals' forces. This field $\left(10^{-7-11} \mathrm{~cm}\right)$ is studied by the classic sciences of physics and chemistry. Yet our universe is ultimately composed of much smaller, subatomic units; at present it is doubtful whether their rules and laws of behaviour are valid also for the greater and more complicated entities of study, such as the earth.

In the upper part of this scale of natural sciences, we deal with the megascopic field of observations, where the mass force of gravitation is dominant. 


\section{TABLE I}

\section{THE PARAMETER OF LENGTH IN THE NATURAL SCIENCES}

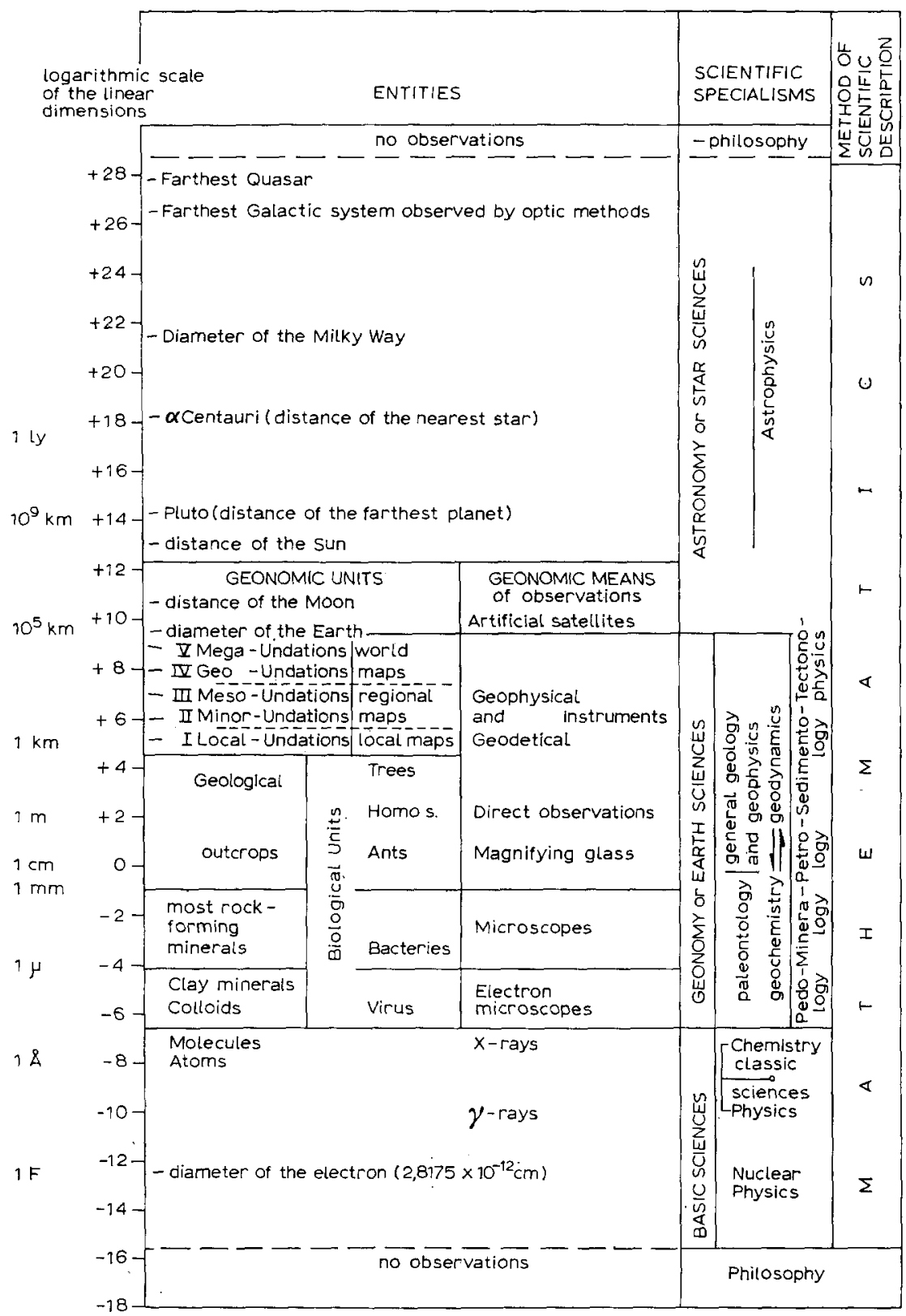


Matter contracts into galactic systems, and inside these systems the contraction proceeds into the formation of stars. The mutual gravitational attraction between the celestial entities governs their relative movements. The upper part of Table $I$ represents the great field of astronomy. In the entities of astronomy (galactic systems, stars, planets) the gravitational and physico-chemical forces cause an attempt at attaining equilibrium.

The controversial influences of gravitational and physico-chemical forces meet in the stars at high levels of energy concentration. The resulting interactions are studied by the science of astrophysics. These equalizing or equilibrio-petal submicroscopic and megascopic processes (equilibrio-petal processes are sequences of events striving for equilibrium), encounter each other also in the earth. Though they interact in our planet at a much lower level of energy-concentration, this level is apparently still high enough to cause the complicated and interwoven chains of reactions, which represent the geological evolution. In still smaller celestial bodies, such as meteoroids and asteroids, the energy level is apparently too low for such chain reactions. These entities are--at least temporarily_-"frozen" into a non-evolutionary state ${ }^{1}$.

The terrestrial battle-field between the physico-chemical and gravitational processes forms the central part of the spectrum of the natural sciences. This central part is studied by the entire group of earth-sciences, called "geonomy". Geonomy encompasses the study of all the non-living terrestrial objects which range in size from colloids (down to about $10^{-6} \mathrm{~cm}$ ) to the entire earth (over $10^{9} \mathrm{~cm}$ ). Even the system earth-moon (close to $4 \cdot 10^{10} \mathrm{~cm}$ ) has recently been incorporated into the field of study of geonomy. Man (with his length of somewhat more than $10^{2} \mathrm{~cm}$ ) occupies almost the (logarithmic) centre of this huge field of the earth sciences, the dimensions of which range from $10^{-6} \mathrm{~cm}$ to well over $10^{+10} \mathrm{~cm}$.

With the help of instruments the geonomist can penetrate with his visual observations downward into levels of smaller dimensions: less than $10^{-4} \mathrm{~cm}$ with the aid of polarization microscopes; less than $10^{-6} \mathrm{~cm}$ by means of electron microscopes.

The chemists and physicists penetrate into still smaller levels of matter by means of $X$-rays, $\gamma$-rays and other devices of observation. But in these basic sciences the fundamental entities are far below the limits of visual perception. Chemists and physicists have to interprete the spatial structures and extensions of their objects by means of indirect visual observations (such as the pointer readings of their instruments).

These submicroscopic fields (studied by the classical basic sciences) are of fundamental interest for the concepts of geological evolutions; because it is in these domains that physico-chemical processes occur, by which the densities of

1 In this relation it seems to be appropriate to classify the scientific objects according to the parameter of mass. But this aspect is not pursued in this review. 
matter are changed thus disturbing the gravitational equilibrium in the earth. These processes are "equilibrio-turbal factors" for the rheological balance in the megascopic field. Thus physico-chemical processes ultimately lead to geodynamic processes which try to restore the gravitational equilibrium.

The geodynamic processes-in action and in their cumulative structural effects-are the central part of the field of study of geology and geophysics (see Table II). Geology is the study of the cumulative effects in the course of time, and in geophysics the attention is focussed on the actual situation and the actual movements. The field, subsurface, and marine geologists, study outcrops on land or under water, as well as the features on the relief. The geophysicists need instruments situated on land, in water, or in air for their observations on the state and movement of matter in depth.

The size of the geonomist (as observing subject) in relation to the size of his object of study determines of course the extent of the area of investigation which he can encompass with his human vision. The field geologist can survey an area of about $100 \mathrm{~km}\left(10^{7} \mathrm{~cm}\right)$ in diameter. The geodynamic processes occurring within the limits of this area are normally described by means of static (fixistic) models. Displacements of the entire field of study of the field geologist with respect to other areas of the earth's surface generally are of no real or direct importance for his restricted purposes of investigation. But phenomena which extend across this frame of direct observation are more easily described by dynamic or mobilistic models of evolution.

This point can be illustrated with the following example. One might try to set up a cube of moist clay with sides of $1 \mathrm{~m}$ on a table in a laboratory; it will spread before one's eyes into a flat cake. This "tectonic process" can easily be described in a "fixistic" way, using the surrounding walls of the laboratory as a frame of reference. But an ant (size about $10^{-1} \mathrm{~cm}$ ) on this table would only see the clay mass invading his territory from the outside. Such an ant-if endowed with mental capacities-would tend to conceive a "mobilistic" model for the scientific description of this process of encroachment. The present author stressed the aspect of "relativity" in the geodynamic models of our time (1962-1966).

The influence of psychology on the preferred model of description is revealed by the following general tendencies in the geonomic concepts of our time. Contemporary Russian authors, such as Beloussov (1966, 1967), SubBotin et al. (1965), born and educated amidst the almost "endless" plains of the Eurasian continental shield-prefer fixistic concepts. Also J. T. Wilson was for a long time opposed to the idea of drift, because his own early field-work in the Canadian Shield did not suggest anything other than long stability and continuity. This author, however, is now converted to drift, as appears, for instance, from his contribution to GARLAND's volume on continental drift (1966).

Present-day English authors on the other hand, such as BLACKETT et al. (1965), educated in the cultural sphere of a seafaring nation, are more disposed 
to accept mobilistic models, considering the continental shield as a kind of KonTiki raft adrift on subcrustal currents. But among the advocates of subcrustal currents the diversification of the opinions is great. For instance, RunCORN (1962) accepts convection currents through the entire mantle, BERNAL (1961) restricts them to the lower mantle, and TOzER (1965) to the upper mantle. The upper mantle is considered to be a barrier to convection by KNOPOFF (1964), a stimulating agent by Vening MeINesz (1964) (phase transitions of olivine), a conquerable barrier if the currents begin at sufficient depth and with sufficient energy according to VERHOOGEN (1965).

The controversies between the fixistic and mobilistic schools appear to be deeply rooted. WeGmann (1956), for instance, lamented: "It is not only a single controversy, but we have to deal with entire knots of antinomies"1.

Nevertheless, both groups have some perfectly sound scientific arguments for their opinions: they mostly differ in their methods of approach, in their premises which have a limited applicability.

If authors interpret the facts of their limited fields of study by hypotheses ad hoc about the character of the adjacent fields and try to cut the Gordian knot of antitheses in that way, it might favour their point of view, but it causes hopeless conflicts with the other aspects of geonomy.

Some polyglot scientists including those of smaller countries, in exercising their sense for compromising may consider the relativity of the premises and the limiting parameters of the processes which are considered to cause the earth's evolution.

The present author is of the opinion that both schools - the fixistic and the mobilistic-might be brought into line with each other, if we strip them of their absolutistic character. In other words, a relativistic way of approach should be attempted, and all premises should be carefully examined as to the limits of their validity (in space and time, and under different physico-chemical conditions).

As an example of the limiting influence of the parameter of time the problem of terrestrial heat flow can be mentioned. BeLoussov (1967) and others see the approximately equal mean value of the continental and oceanic heat flow as an argument against continental drift. On continents the radioactive elements are concentrated in the upper (granite) layer of the crust, missing from the oceanic crust, which latter is poor in radioactive elements. If the continental drifted, blocks of continental crust are assumed to have moved apart over the upper mantle, removing most of the radioactivity from the regions now occupied by oceans. Heat flow through ocean floors should therefore be only one third of that through continents.

The fact that the observed heat flow through the floors of the oceans and

1 "Manchmal handelt es sich nicht nur um einen Widerspruch, sondern um ganze Knäuel von Antinomien". 


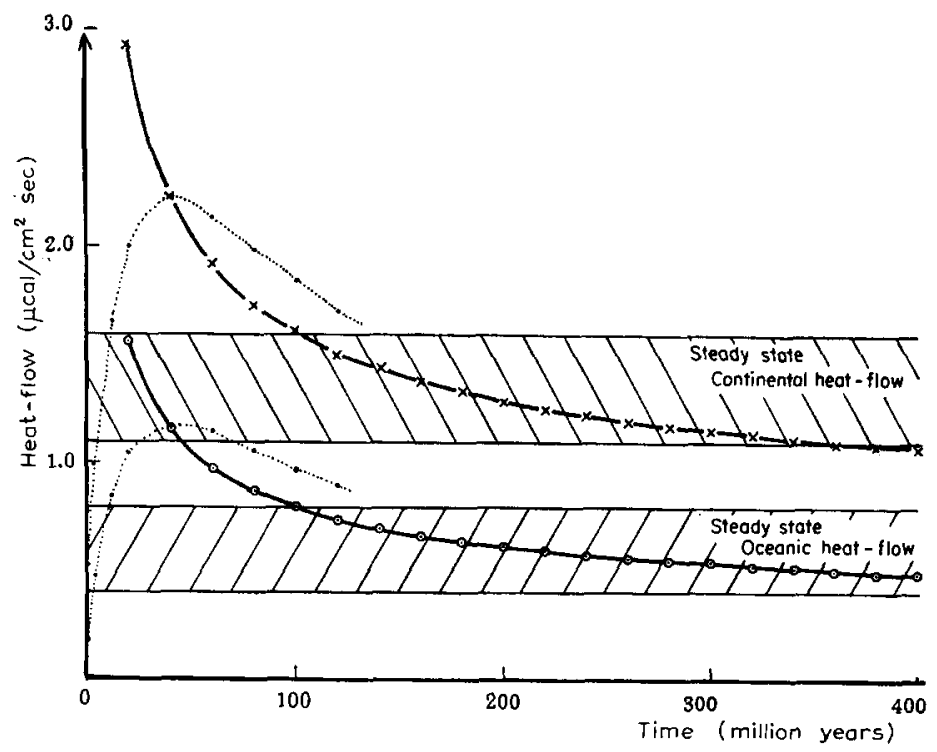

Fig.1. The heat flow in a static and a dynamic earth, according to ScHuiling (1966).

continents appears to be of the same order of magnitude, might tentatively be explained by assuming that the distribution of the radioactive elements is different, being scattered in the undifferentiated sub-oceanic upper mantle in far higher concentration than in the already differentiated subcontinental parts of the upper mantle. In that case continental drift would be impossible, states the "fixist" Beloussov (1967, p.6).

However, the premise of an undifferentiated suboceanic upper mantle is contradicted by the low radioactivity of oceanic basalts. Moreover, ScHUILING (1966) discussed the heat-flow process during the last one or two hundred millions of years. Considering the influence of time the present author comes to the basic conclusion that continental drift itself might be the explanation of the approximate equality of oceanic and continental heat flow. Thus, by a closer analysis of heatflow data, based on the limitating effects of parameters of time, Schuiling arrived at just the opposite, mobilistic point of view.

Another instance of the limiting effects of the geonomic parameters on the applicability of the concepts is provided by Nieuwenkamp's neo-Huttonian theory of the persedimentary origin of granites.

NieUWENKaMP (1965), Gregor (1967) and other adherents to neo-Huttonian models of cyclic processes often quote Hutton's famous phrase: "We find no vestige of a beginning and no prospect of an end". This might be true for the study as directed to the sialic shield itself, with its recurrent cycles of sediments-granitessediments. This concept, however, is limited to the age of these shields. The petrologist can study them over a period of about three and a half billion years. 


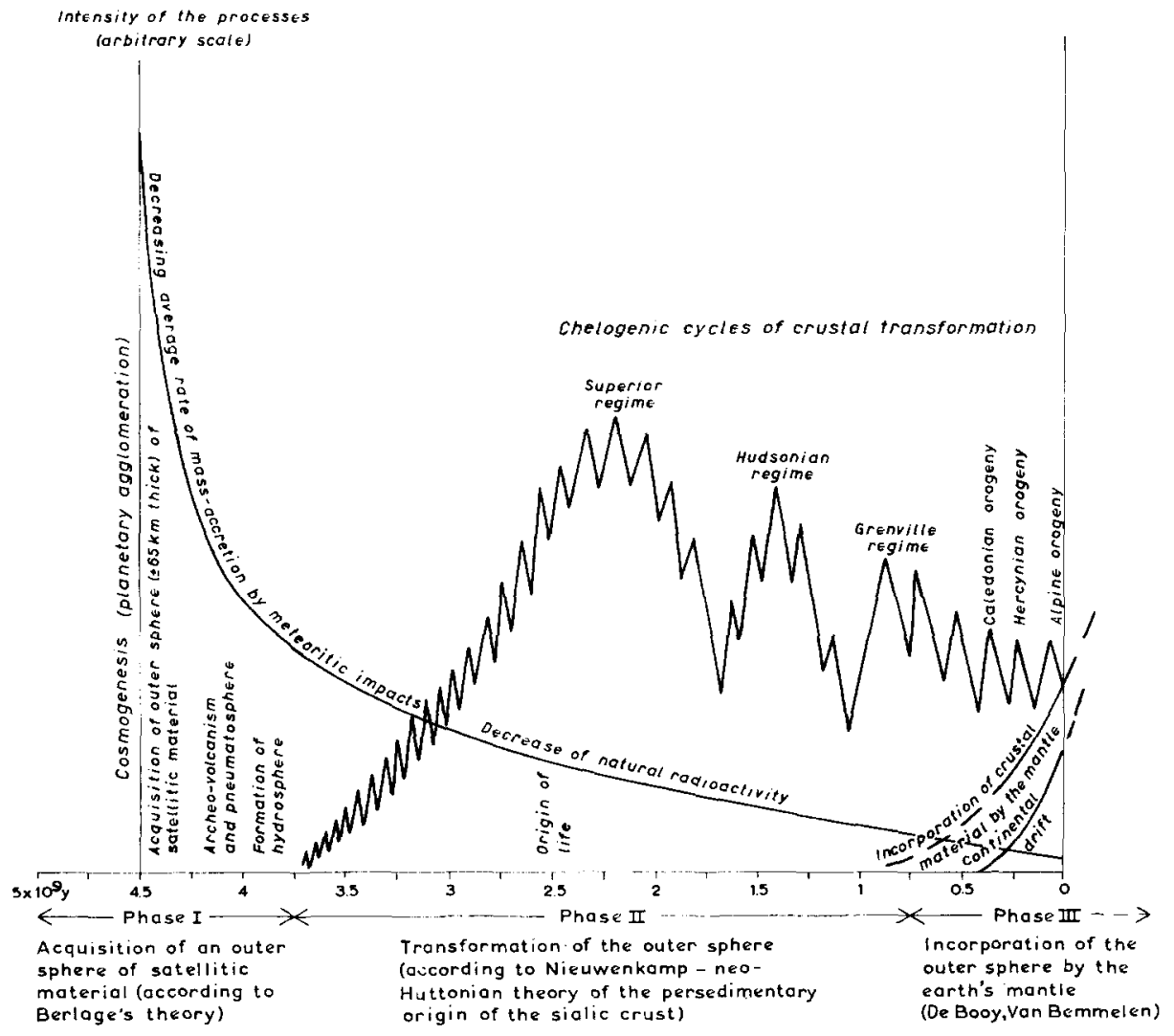

Fig.2. The three main phases of the earth's evolution. (After VAN BEMMELEN, 1966a, fig.1.)

The cycles may be "countless" but they are not "endless". Of course there was a beginning, namely the creation of the sun's planetary system, about $4 \frac{1}{2}$ billion years ago. And there will come an end to this type of crustal evolution, though we do not yet know how and when. The recent work by DE BooY (1966) provides a strong indication that fundamental changes in the relations between sial and sima are already discernable in the last few hundred million years of the global evolution. (See also: VAN BEMmELEN et al., 1967).

So the persedimentary concept regarding the origin of granites as based on the premise of recycling has its natural limitations in time. It appears to be valid only during the second major phase of the earth's evolution. Once more it is evident that the parameter of time is a limiting factor in geological concepts. This will be further discussed in the next section. 


\section{THE PARAMETER OF TIME IN GEONOMY}

Table II shows the relations between length and time in geonomy. In combination these two dimensions determine the distances covered in the course of time, i.e., the mean velocity of the geonomic processes. Entities moving at or above the surface of the solid earth generally have a greater mean velocity, than the geodynamic processes beneath the earth's surface. This is because the former are not hampered by confining pressures. Explosion phenomena in volcanic necks are only an apparent exception to this rule. The boundary between sub-surface and supra-surface body-movements lies at the line which coincides with a mean velocity of about $10 \mathrm{~m} /$ year (see Fig.3).

The maximum surface velocities are attained by ignimbrites and nuées ardentes, which are almost frictionless suspensions of particles in hot gases (mean velocities of some tens of meters up to over one hundred meters per second).

At still higher velocities the particles of matter are not permanently displaced with respect to their surroundings, but wave-like motions of elastic deformations are propagated through the matter. These wave-like motions are, for instance, the tsunamis in the hydrosphere and the seismic waves in the solid earth.

Even higher velocities are represented by the left lower corner of Table II.

\section{TABLE II}

THE RELATIONS BETWEEN THE PARAMETERS OF LENGTHS AND TIME IN GEONOMY

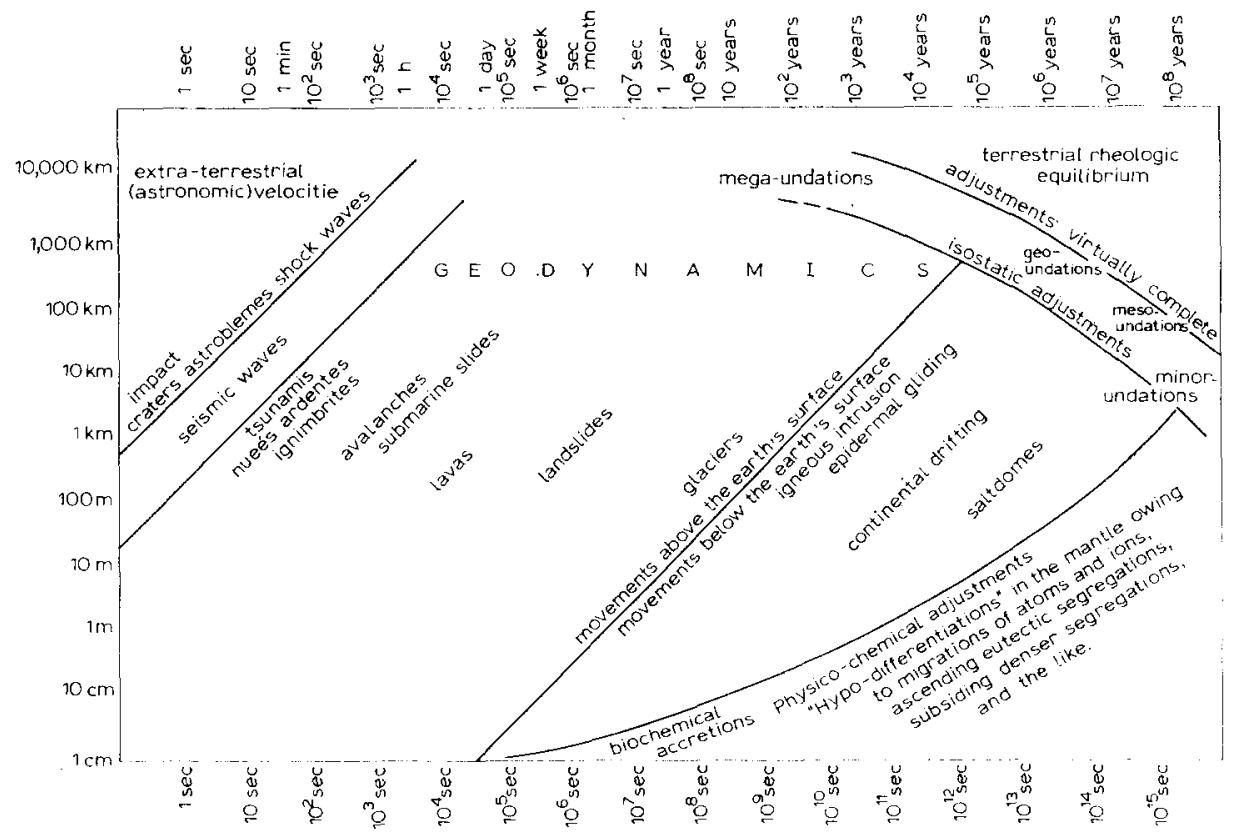




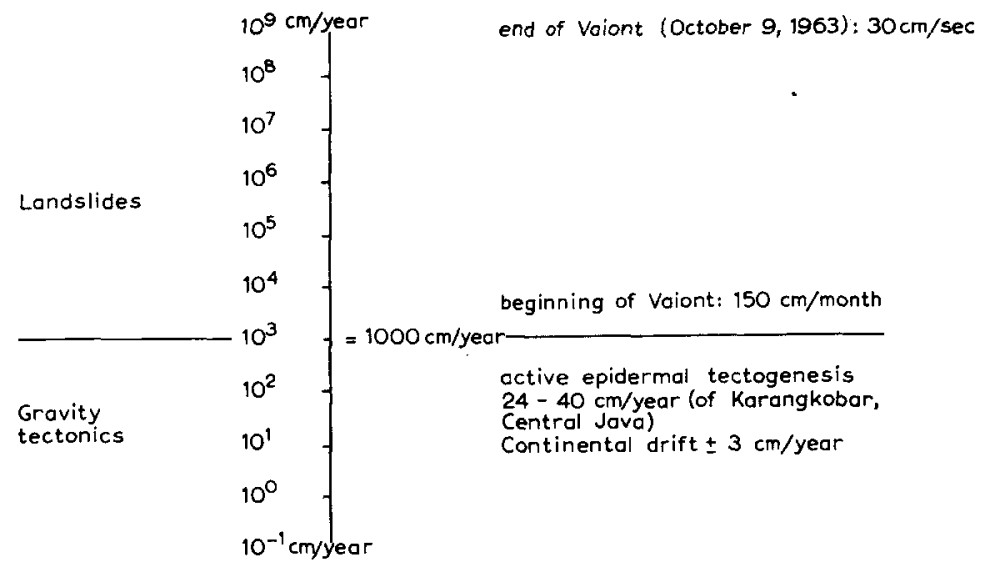

Fig.3. The gradual change of speed from various dimensions of gravity tectonics to landslides (logarithmic scale). For the speed of the Vaiont slide see Selli et al., (1965) and Semenza (1965). The speed of the active gravity tectonics in the Karangkobar area of central Java has been determined by the author by means of triangulations with an interval of five years (VAN BEMMELEN 1949, p.610). The speed of continental drift can be estimated by means of paleomagnetic and geotectonic observations. See, for instance, the estimation of the speed of the opening of the Thulean Basin in VAN BEMMELEN (1966c).

These velocities occur primarily outside the earth in the relative movements of celestial bodies. When these objects (such as meteorites, asteroids, comets) hit the earth they can form impact craters and huge "astroblemes", as suggested by DieTz (1961). During such a very brief cataclysm enormous amounts of extraterrestrial energy are shot into the crust and even into the top part of the mantle. These events might be compared with huge nuclear subsurface explosions. They may cause magma chambers of various dimensions, and the earth will need many millions of years of geonomic evolution for getting rid of this input of extraterrestrial energy.

In the left upper corner of Table II the influence of time becomes preponderant. The greater deformations of the geoid, such as mega-undations with diameters of about $10,000 \mathrm{~km}$, can sustain deviations from isostatic equilibrium only during a relatively short time. The gravitational anomaly fields of mega-undations (as determined by artificial satellites) are merely the instantaneous determination of the residual anomalies of a process in flux. The gravimetric anomaly fields of the mega-undations would disappear in the course of some thousands of years if there were not a deep-seated source of disturbance, viz., a mass-circuit in the mantle, which continuously counteracts the process of gravitational spreading on top.

Deviations from isostatic equilibrium of the size of geo-undations (such as geosynclines and mid-ocean rises, with diameters of about 1,000 km) may take about a million years for their isostatic adjustments, whereas meso-undations 
with diameters of a few hundreds of kilometers (like the Alps) may still show a residual negative isostatic anomaly more than 10 million years after their uplift.

The fields of potential energy, caused by minor undations with diameters of about $10 \mathrm{~km}$ (such as plutonic and gneissic domes) are generally removed by erosion, long before they could be eliminated by isostatic adjustments.

In the right upper corner of Table II we find the effects of slow migrations of atoms and ions caused by physico-chemical gradients, which may have great cumulative effects in the course of time. The adjustments of the physico-chemical equilibrium proceed at a submicroscopic scale. But in the course of time they do locally cause a differentiation of the chemical composition in the mantle. This process has been called "hypodifferentiation" by the author in order to distinguish it from the classic models of differentiation in intracrustal pockets of magma.

The slow physico-chemical adjustments in the mantle, in the upper right corner of Table II, will disturb the rheological equilibrium in a progessive and cumulative way. They are the fundamental cause of the geodynamic processes in the central part of the diagram. But, in order to understand the geodynamic effects of the chain-reactions resulting from the liberation of free energy in the earth, the physical and chemical nature of the earth's structural zones ('Stockwerke"), have to be discussed first.

THE PHYSICAL AND CHEMICAL CHARACTER OF THE EARTH's "STOCKWERKE"

The earth consists of a number of concentric zones of different physical and chemical properties. The model of the earth's internal constitution has been obtained by various geophysical and geochemical methods. Examination of the earth by means of seismic waves showed changes of the seismic properties in a radial sense. This led to the distinction of a number of zones, marked $A-G$ by Bullen (1959). Observations on Rayleigh waves have suggested that there are not only radial but also lateral variations in the seismic properties, at least down to depths of some hundreds of kilometers.

Our present-day concepts on the physico-chemical properties of the earth's "Stockwerke" are much more sophisticated than previous models. Until about 12 years ago little attention was paid to the meaning of the increase of pressure with depth. Neuhaus (1967) points out that nowadays it is possible to imitate experimentally all temperature and pressure conditions which might exist inside the earth. That means pressures upward to about $3.5 \mathrm{mbar}$ (with the aid of shockwaves) and temperatures up to $5,000-6,000^{\circ} \mathrm{C}$.

The results of high-pressure and high-temperature experiments permit the establishment of two general principles: 


\section{TABLE III}

THE STRUCTURAL ZONES OR "STOCKWERKE" OF THE EARTH

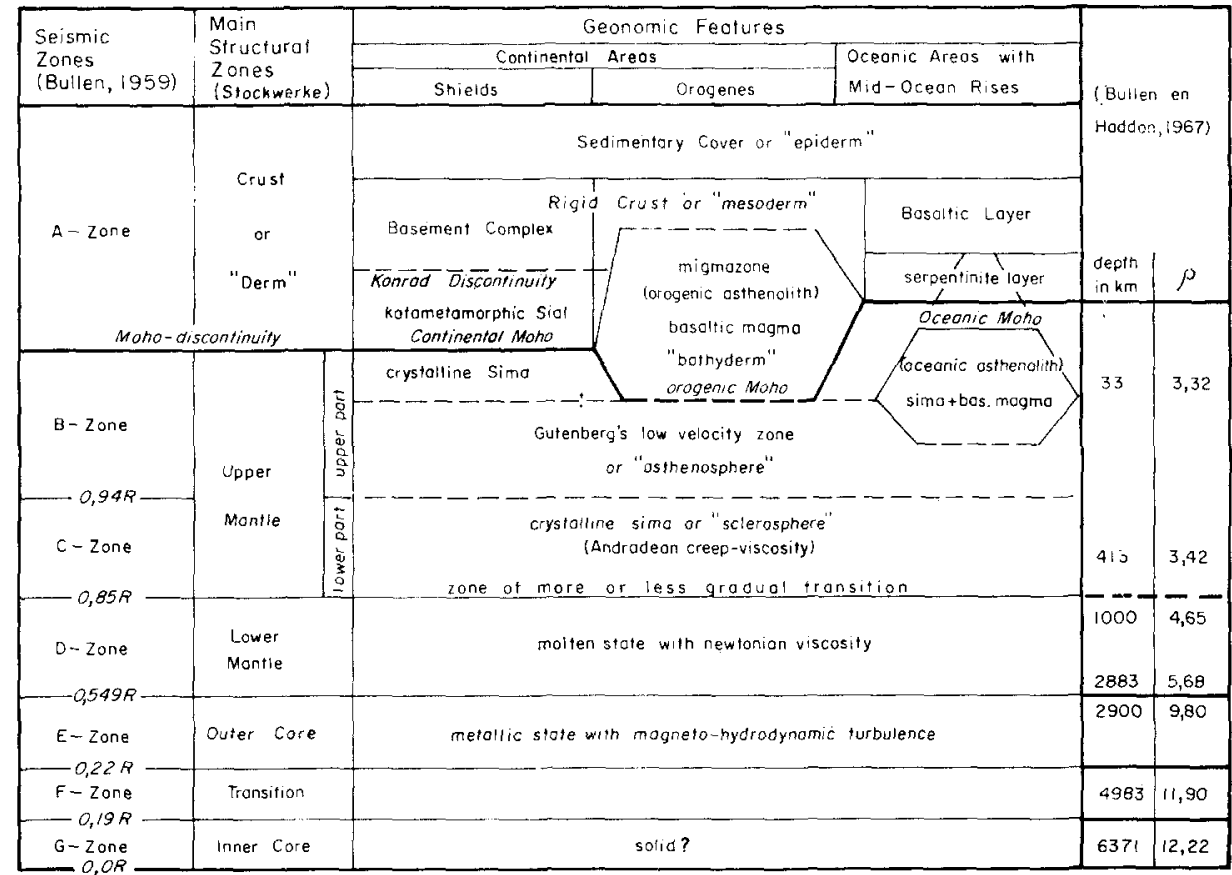

(1) Pressure-coordination rule. Increasing pressures promote compaction of matter and increase of the coordination number of chemical entities. For instance:

\section{Graphite (3) $\stackrel{\Delta^{P}}{\rightarrow}$ Diamond (4)}

Quartz (4) $\underset{\rightarrow}{\rightarrow}$ Stishovite (6)

Decrease of pressure (or increase of temperature) promote more open chemical structures.

(2) Pressure-valence rule or rule of homology. The valence states of crystalline phases changes with increasing pressure (that is with increasing depth) in the same way as the normal pressure-valence state in the upward sections of homologous series in the periodic system. For instance:

Diamond (4) (insulator) $\underset{\rightarrow}{\Delta} \mathrm{Pi}$, Ge (4) (halfconductors) $\underset{\rightarrow}{\Delta}$

Sn (I) met. (6) $\underset{\rightarrow}{\rightarrow}$ Sn (II) met. (12) (supraconductor)

These rules provide us with an insight into the possible changes of the 
states and properties of matter with depth. The physico-chemical changes in the state and composition of the earth's "Stockwerke" with increasing depth are much more complex, than formerly supposed by the advocates of the model of thermal convection currents. In the latter models it has been noticed that the mantle is chemically quasi-homogeneous and mere expansions or contractions by heating and cooling are thought to be able to lift matter from the base of the mantle to its top during "half turnovers". According to modern high-pressure and high-temperature experiments, however, it is very improbable that such a condition of quasi-homogeneity of the chemical composition of the mantle is fulfilled. Authorities now agree that there are two distinct seismic boundaries, the Mohorovičić discontinuity at the base of the crust and the Oldham-discontinuity at the base of the mantle. However, the seismic transition between the lower and the upper mantle is more or less gradual. The actual mean densities of the mantle material also change more or less gradually with depth. Adaptations of the mean density to changes in the confining pressure (i.e., to the depth) seem to be possible according to contemporary high temperature-high pressure experiments. Therefore, it is difficult to determine seismically or gravimetrically the depth of the boundary between the lower and the upper mantle. This is of importance for the author's concept of the mechanism of mega-undations, for this concept involves upwarps and downwarps of the transitional zone between the lower and the upper mantle with amplitudes of more than $100 \mathrm{~km}$ (see Fig.4).

The controversy about the nature of the "Moho" at the base of the continental crust (isochemical phase-transition or change of chemical composition) seems now to be settled in favour of the latter interpretation (RINGwOOD and GREeN, 1966; RINGWOOD, 1967). This implicates that the lower part of the crust in cratonic shields does not necessarily have a basaltic or gabbroic composition. It is probably composed of sialic matter in a kata-metamorphic state (DEN TEX, 1965). Underneath young mountain systems the Moho lies deeper than the subcratonic Moho (at 35-70 km instead of 30-35 km depth). Between the elevated crystalline basement complex and the depressed orogenic Moho a body of mixed composition has been formed, which provides the isostatic buoyancy. These bodies were called "orogenic asthenolith" by the author. The upper parts of the asthenoliths underneath meso-undations (mountains ranges and island arcs) consist of migmatic rocks and sialic magma, with upward apophyses of plutonic and volcanic intrusions. Basaltic magma, segregated from the upper mantle, probably prevails in the lower part of the orogenic asthenoliths.

The Moho at the base of the shields is a sharp seismic boundary, whereas the Moho at the base of orogenic asthenoliths is much less distinct. It actually is a more or less gradual transition to the upper mantle. The base of these asthenoliths presumably is a "mixed" layer, composed of crustal matter (sial) and of the upper mantle material (sima). CoOK (1962) speaks of a "mantle-crust mix". It is also possible that the lower part of an orogenic asthenolith consists of a 
mixture of peridotite and basalt magmas, especially underneath oceanic ridges (such as the Tonga-Kermadec Ridge).

Another type of asthenolith occurs underneath the mid-ocean rises. These buoyant bodies are much wider (about $1,000 \mathrm{~km}$ instead of the $100-200 \mathrm{~km}$ width of the orogenic asthenoliths). Moreover, these "oceanic asthenoliths" are situated underneath the oceanic Moho discontinuity. Their mean density is somewhat over 3.0 and they appear to be entirely embedded in upper mantle matter with a mean density of about 3.4 (TALWANI et al., 1965). The oceanic asthenoliths also have a somewhat lower mean velocity in the seismic waves. It seems probable that these buoyant bodies of "abnormal mantle matter" are mixtures of normal mantle matter and intrusions of basaltic magma. The latter probably is segregated by the upper mantle.

The oceanic Moho lies at a much shallower depth (10-12 km below sea level) than the continental Moho (30-35 km depth). The oceanic Moho is now seen as the transition between a serpentinite layer and the upper mantle matter, which might have a pyrolitic composition (about three parts of peridotite and one part of basalt according to RINGWOOD, 1967).

The continental and the oceanic Mohos definitely have a different geochemical and structural meaning. Nevertheless, in later years several instances have become known of transformations of continental Mohos into oceanic Mohos during the geological evolution of a certain area (Carribbean Sea, VAN Bemmelen, 1958; Gulf of Mexico, Van Bemmelen, 1964a, p.422; Japan Sea, Beloussov and Ruditch, 1961; the Mediterranean Basin and the Black Sea, etc., see VAN BEMMELEN, 1966a, p.114).

These transformations of a continental into an oceanic Moho occurred occasionally without considerable lateral movements of the overlying crust (Gulf of Mexico; Black Sea, see Semenenko et al. 1967, fig.3, p.54). Accepting the fact that the continental Moho is apart from a geophysical also a chemical boundary, this implies that great changes in the mean chemical composition of the crust took place during this transformation. The upper mantle apparently invaded, impregnated, injected, corroded, destroyed, or dissolved the overlying sialic crust in a more or less extensive way. In such regions the crust is assimilated ("oceanized") and its sialic components are evidently transported, not sideward (accompanied by orogenesis) but downward into high-density mineral phases. This process has been called oceanization of the Mediterranean type (VAN BEMMELEN, 1966a). It can be described by fixistic concepts and it is, understandably, favoured by Beloussov.

But Beloussov is of the opinion that this Mediterranean oceanization is the only possible way of removal of the sialic crust from certain areas of the earth's surface, and that it would be responsible for all disconformable oceanic coasts where the continental structures are truncated (Beloussov, 1966, p.314). Is not this an extrapolation of an otherwise sound concept beyond the boundaries 
of its applicability? The disconformable coasts truncating the tectonic trends of the shields around the Atlantic and Indian Oceans have many features which are in favour of continental drift (mobilism). The Atlantic and Indian Oceans are, moreover, characterized by mid-ocean rises with rift systems on their crest. The world rift system is conspicuously absent in sea basins of the Mediterranean type, such as the east Asiatic marginal seas. The formation of the Atlantic and Indian Oceans has been called the Atlantic type of oceanization by the present author (1966a). This type of oceanization has a mechanical character, namely the spreading under gravity of the top part of mega-undations. This is in contrast to the Mediterranean type, which has a chemical character (VAN BEMMELEN, 1966a, p.114).

\section{A MODEL OF THE CHAIN REACTIONS OF THE EARTH'S EVOLUTION}

In the foregoing sections the importance and the interrelations of some parameters of geonomy has been discussed (Table I and II), and a model of the main geodynamic "Stockwerke" has been suggested (Table III). This leads to a concept of complicated chain reactions which are triggered by the liberation of endogenic energy. We will review the possible character of some of the processes which occur in the earth's "Stockwerke", starting with the innermost core.

G zone

The inner core is considered to be solid according to seismic data. The mean density might be 12.22 (BuLLEN and HADDON, 1967). The modern technique of high-pressure and high-temperature experiments can give some insight into the possible composition and state of the matter in this core. NeUHAUs (1967) suggests that $\mathrm{Fe}$ and $\mathrm{Ni}$ are less dominant than was accepted by older concepts. Chalcogenides, nitrides, carbides, phosphides and some oxides, occurring as such under normal pressure conditions at the base of the crust, might in the inner core already be in a completely metallic state (but not Si!). How much will conditions and contingent processes at the centre of the earth differ from our anthropomorphic concepts based on our technological activities such as the operation of blastfurnaces?

F zone

Seismic data indicate the presence of a transition zone between the inner and the outer core, with a mean density of 11.90 . As the outer core ( $E$ zone) is already in a state of turbulent motions, we may suppose that in this transition zone endogenic energy is somehow released, as the driving force for the movements in 
the $E$ zone. Holmes (1964, pp.991-993) is of the opinion that this energy is not likely to be of a radioactive character. The latter energy source was presumably very important during the earliest stages of the earth's history, when short-lived isotopes were still present, but the mantle would become too hot if radioactivity still were the enduring driving force of the central dynamo.

The endogenic energy seems to be a rather steady flow of free energy lasting throughout the earth's history. Liberated in the inner parts of our planet, ascending in various states and ways, and intermittently locked up in intermediate stations of potential energy; finally it is lost into space as a low-level radiation of heat. As possible ways of release of potential free energy from such intermediate stations we may surmise several physico-chemical processes: phase-transitions, reductions of the compaction of matter, gradual secretion of chemical fractions by atomic and ionic migrations. Perhaps a gradual decrease of the factor of gravitation $(G)$ in the course of geological time, as was suggested by DIRAC (1938), might be of influence on this liberation of a more or less steady flow of energy in the transition zone of the core.

E zone

This energy in the transition zone is introduced into the outer core. This is the first step on its way outward. It encountered matter in a metallic state (mean density 9.80$)$ and of high temperature $\left(5,000-6,000^{\circ} \mathrm{C}\right)$. Any production of matter of relatively different density as well as the temperature effects of endothermic or exothermic physico-chemical processes must necessarily disturb the rheological equilibrium in this outer core. Its matter entered into a state of magneto-hydrodynamic turbulence, which is now held responsible for the earth's magnetic dipole field. The velocity of the revolving currents in this central dynamo might be of the order of $20 \mathrm{~km} /$ year, as is indicated by the westward drift of anomalies along the boundary with the mantle.

D zone

The second step of the endogenic energy in its way outward is its transformation into other forms on passing from the core to the mantle. This transformation may have the character of phase changes, segregation of chemical constituents, positive and negative heat balances of the physico-chemical reactions involved.

These processes influence the mean density of the matter at the base of the mantle, which is about 5.68. Consequently, the rheological equilibrium of the mantle is locally disturbed. In areas were the mean density at the base of the mantle is reduced the overlying columns of matter are pushed up, by buoyancy, whereas in areas of relatively high densities the matter tends to spread sidewards, replacing 


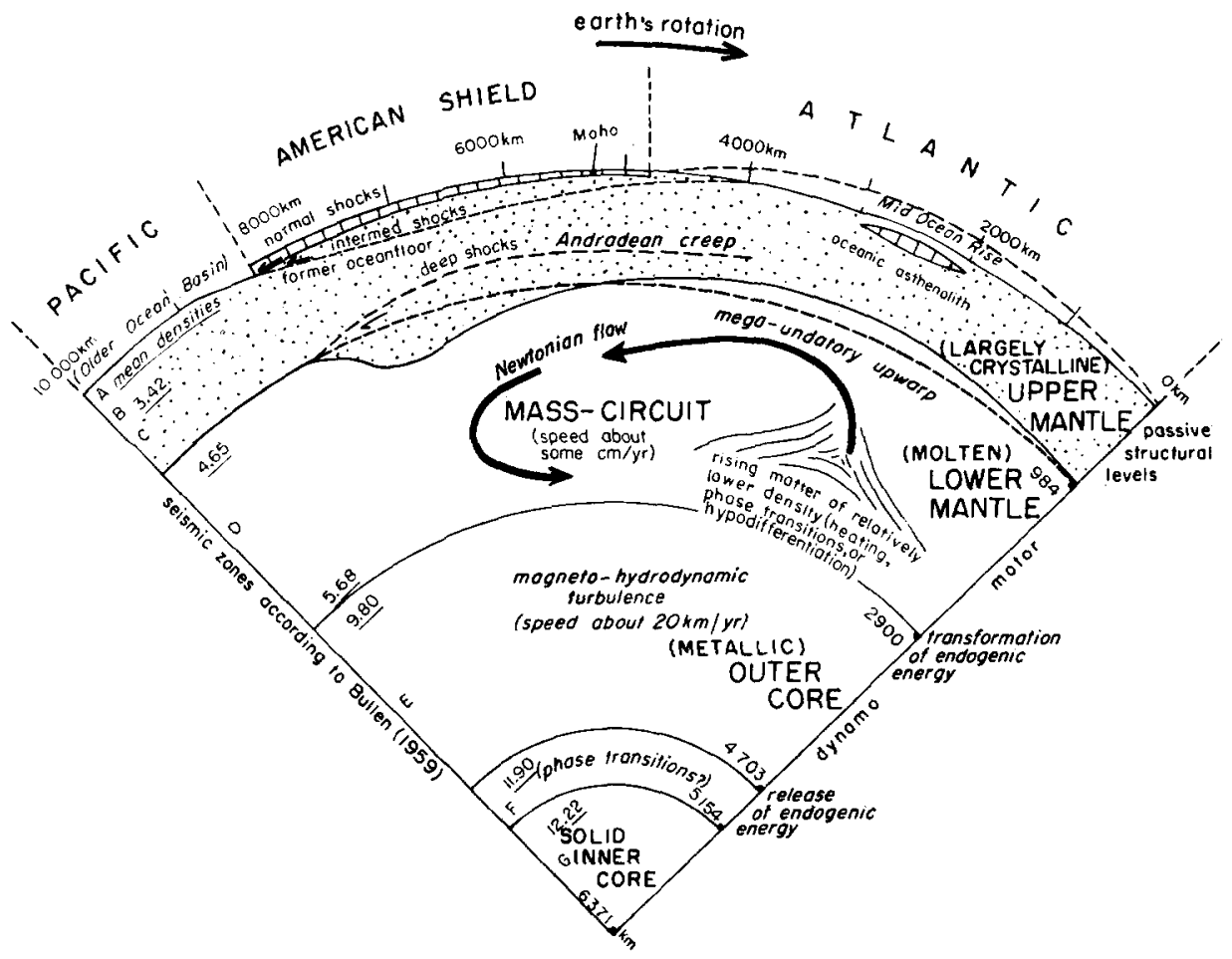

Fig.4. Model of the mechanism of mega-undations according to the present author.

the matter at the base of the rising column. In this way mass circuits are generated in the lower mantle. Such mass circuits are not necessarily thermal convection currents, because it is not certain that the condition of chemical homogeneity is fulfilled. Neither do we know whether the movements have the character of Newtonian laminar flow, or have a rather more turbulent character (KNOPOFF, 1964).

The up- and downward-moving columns of the mass circuits in the lower mantle cause upwarps and downwarps of the boundary zone between the lower and the upper mantle; at the surface of the earth also radial, epeirogenic movements are generated in this way.

Judging the speed of these mass-circuits by the mean velocities of really extensive epeirogenic changes of level at the surface, the velocity of the currents in the lower mantle is not more than some centimeters per year. Moreover, the various fields of potential energy in the lower mantle cause anomalies in the earth's gravity field, which have very small gradients and very great extent. By means of observation of the orbits of artificial satellites, such gravitational anomaly fields are registered as first-order deformations of the geoid, which we call megaundations. Although the upwarps and downwarps of the boundary between the lower and the upper mantle may attain amplitudes of more than a hundred kilo- 
meters, this deep-seated warping cannot yet be detected by the current seismic and gravimetric methods (see p.91).

Because of its higher temperature the matter of the lower mantle probably has a lower viscosity than that of the upper mantle. Moreover, the mean density of the lower mantle material is higher than that of the upper mantle (4.65 and 3.42 at depths of 1,000 and $413 \mathrm{~km}$, respectively, according to BULLEN and HADDON, 1967). Rising columns of matter in the lower mantle therefore will not be able to penetrate through the upper mantle. They will mushroom and spread from the upwarps toward the downwarps of the boundary zone between the $C$ and $D$ zones (compare Fig.4).

As has already been suggested by BERNAL (1961) such convective mass circuits are restricted to the lower mantle. They are the very motor for most geodynamic movements in the outermost $1,000 \mathrm{~km}$ of the earth. Their free energy is transmitted to the outer mantle in several ways. In the first place, the radial mega-undatory deformations create fields of potential energy in the outer zones $(A-B-C)$. Presumably of lesser importance are the heat effects in the boundary zone, the drag effects by the lateral flow in the mushrooming tops of the mass circuits in the lower mantle, and phase transitions in this boundary zone. The $A-B \sim C$ zones are the mechanically more or less passive entities of the planetary engine.

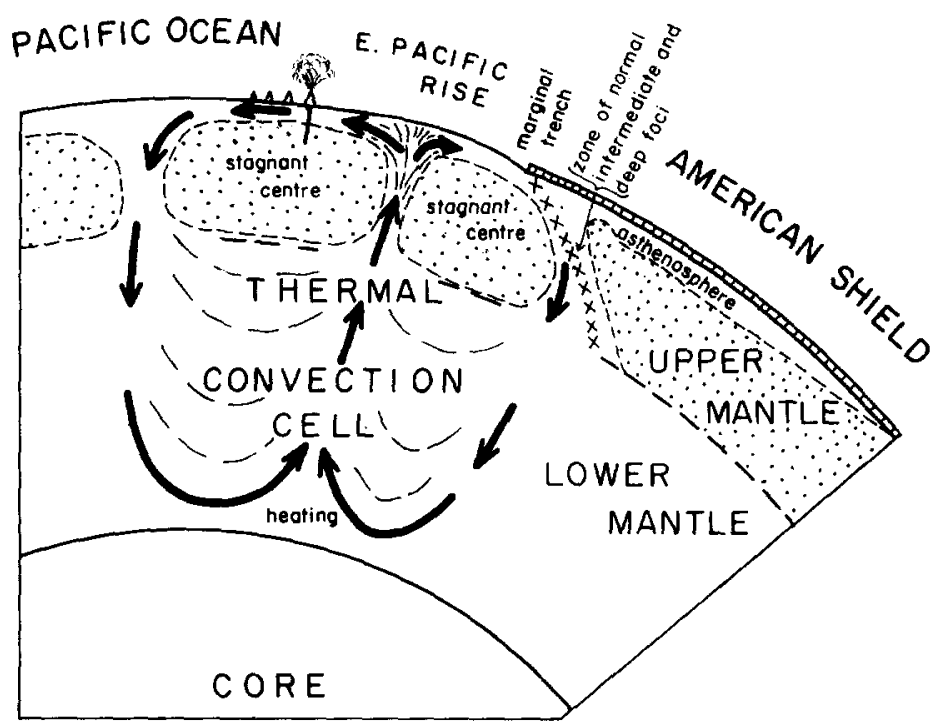

Fig.5. Model of the mechanism of thermal convection currents according to WILSON (1963, fig.4). 
C zone

The upper mantle can be subdivided into two spheres. The lower one is the seismic $C$ zone of BuLleN's (1959) classification. It probably has a crystalline state; thus it has an Andradean viscosity caused by intracrystalline creep phenomena (Orowan, 1965). Elastic deformations may accumulate until sudden movements of relaxation occur, which cause deepseated and intermediary foci of earthquakes (maximum depth $-720 \mathrm{~km}$ ). The crystalline matter of the $C$ zone is probably much stronger than the molten, non-crystalline matter of the lower mantle, and it has been called the "sclerosphere" (LuSTICH, 1962).

On account of an analysis of the Rayleigh numbers KNOPOFF (1964) also comes to the conclusion that in the $C$ zone no convective flow movements are possible. It is deformed by a mechanism of huge glide planks, as is characteristic for matter with an Andradean viscosity (SCHMIDT, 1932; HARRINGTON, 1963; OROWAN, 1965).

B zone

In the upper part of the lower mantle a more or less continuous zone occurs with relatively lower velocities of the seismic waves. The vertical vibrations (e.g., of Rayleigh waves) are transmitted through this channel more rapidly than horizontal ones, which suggests that its matter has a foliation caused by glide planks of Andradean flow (see also HoLmes, 1964, p.950). It has a greater depth underneath the continents $(80-220 \mathrm{~km}$ ) than under the oceans (about $60 \mathrm{~km}$ ). This seismic zone is indicated by various names, such as "low-velocity channel", "waveguide layer", or "asthenosphere".

In this zone the reduction of the viscosity by the rise of temperature with depth presumably is somewhat greater than the increase of viscosity by the rise of confining pressure. In this zone of relatively reduced viscosity the upper mantle material may even have segregated a magmatic eutectic phase of basaltic magma. This layer will act as a kind of lubricating zone between the outermost part of the upper mantle with the crust on top of it and the sclerosphere underneath.

\section{A zone}

Units of the overlying A zone can move separately and autonomously over this lubrifying B zone. On land the blocks of (sub)continental size are bounded by strike-slip faults of the San Andreas type (called geosutures by RoD, 1967), and at sea the structural entities of the A zone are bounded by faults of the Mendocino type. The autonomous character of the movements of these crustal units, bounded at all sides by structural discontinuities, is indicative of the gravitational character of these mutual horizontal displacements. According to the present 


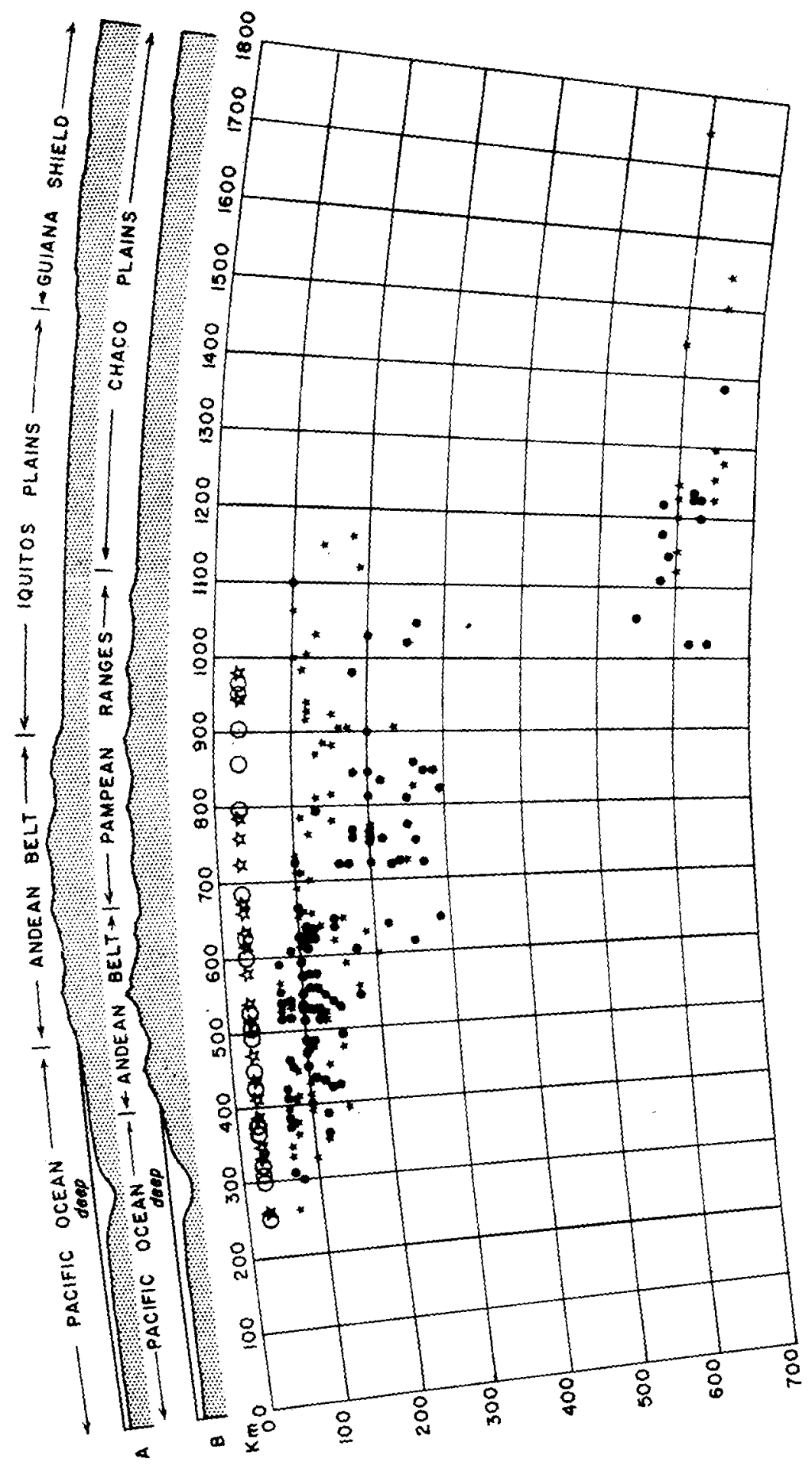

Earth-Sci. Rev., 3 (1967) 79-110 
author the crustal units are neither dragged, nor pushed by convection currents in the underlying mantle. They move because of their inherent potential energy, present in all their particles of mass. This potential energy has been introduced into the outer zones $(A-B-C)$ by their mega-undatory radial movements.

The crest of the mega-undatory bulges spread under gravity towards the adjacent downwarps. During this process the $A-B-C$ zones are subdivided into more or less horizontal glide-planks separated by zones of reduced Andradean viscosity. Relaxations of elastic deformations cause earthquakes at normal, intermediary and deep levels. The higher units move farther and faster than the underlying ones, just as occurs during the spreading of a tilted pile of books.

This mechanical picture is confirmed by the analyses of the focal mechanism of well-observed shocks (RITSEMA, 1964). The concept of convection currents spreading from the Pacific Ocean and diving with a dip of about $60^{\circ}$ underneath the surrounding continents is at variance with the observation that the foci are distributed in more or less distinct horizontal levels (HARRINGTON, 1963).

The present author suggests that the circum-Pacific continents themselves are the active elements, which encroach over the Pacific floor pushing the latter downward. This pictures, for instance, are confirmed by the structure of the Japan Trench (LudwiG et al., 1966). The Japan Trench shows step faulting at its Pacific side, where the oceanic crustal plate is being depressed in response to the load exerted by the encroaching island arc (cf. Fig. $7 \mathrm{a}, \mathrm{b}$ ).

The lateral displacements and rotations around vertical axes of crustal units with respect to adjacent blocks and with respect to the earth's axis of rotation are confirmed by paleomagnetic researches. They can be interpreted as the result of their own potential energy acquired during mega-undatory deformations of the geoid.

These drifting movements, in turn, bring indirect effects into action, such as orogenic cycles at the prow of the drifting shields, extension phenomena in their stern, and the opening-up of new ocean basins in their wake (oceanization of the Atlantic type, VAN BEMMELEN, 1966a).

The ocean rises in the middle of these new ocean basins are the result of the segregation of basaltic magma from the elevated matter of the upper mantle in the crustal part of a mega-undation. In these upwarps the confining pressure is greatly reduced due to spreading and the process of Atlantic oceanization; meanwhile the geothermal gradient has become steeper. The crests of the megaundations will shift in the course of the geological evolution. The present picture

Fig.6. The distribution of normal, intermediary and deep earthquake foci under South America, according to HARRINGTON (1963). Solid stars = foci of earthquakes north of $19^{\circ} \mathrm{S}$; solid circles = foci of earthquakes south of $19^{\circ} \mathrm{S}$; open stars and circles = foci of shallow earthquakes north and south of $19^{\circ} \mathrm{S}$. respectively. $\mathrm{A}=$ cross-section drawn between $1^{\circ} \mathrm{S} 70^{\circ} \mathrm{W}$ and $8^{\circ} \mathrm{S} 82^{\circ} \mathrm{W} ; \mathrm{B}=$ cross-section along $30^{\circ} \mathrm{S}$. 


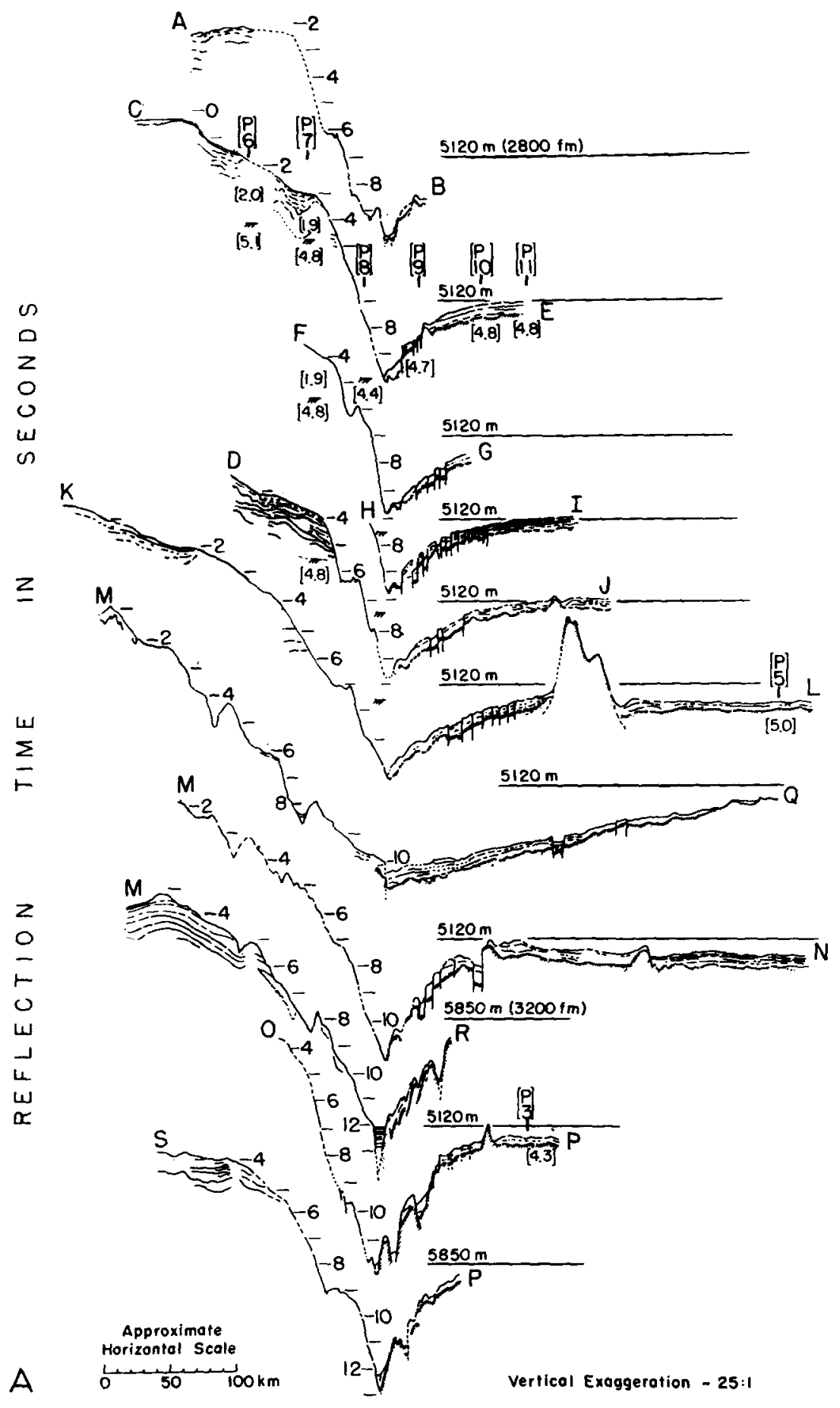

Earth-Sci. Rev., 3 (1967) 79-110 


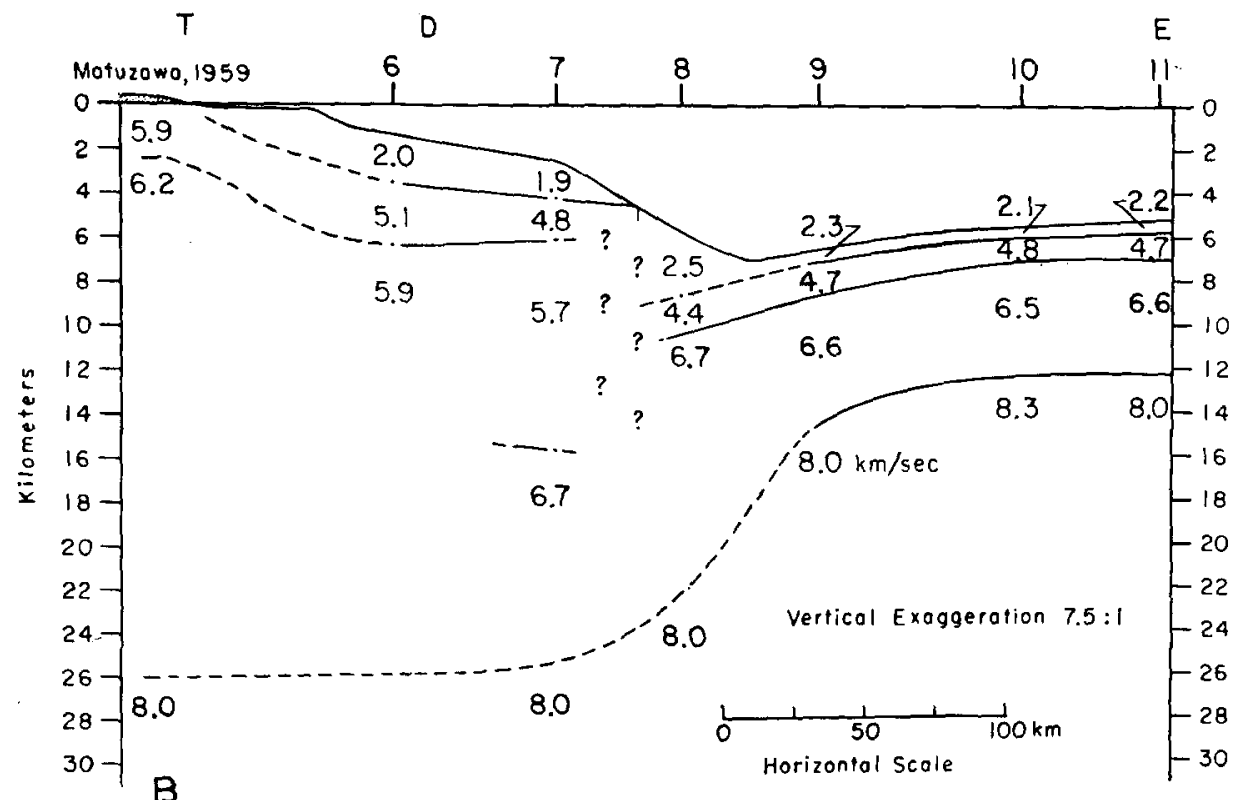

Fig.7A. Seismic reflection profiles across the Japan Trench. (After Ludwig et al., 1966, fig.2, p.2123.) The Japan Trench evidently has an asymmetric structure. At the Japan side the refiection data show sedimentary strata which steepen toward the axis of the trench. See for instance the third profile from the bottom. This may be explained as the oceanward flank of a broad crustal fold (island arc) with meso-undatory dimensions (width some hundreds of kilometers).

At the Pacific side the dominant features are sub-vertical step faulting, accompanied by some tensional rifting. This indicates the progressive subsidence of the ocean crust on approaching the axis of the trench by means of differential vertical movements.

Five mechanical models might be conceived for the formation of this trench, three of them possessing a symmetrical character. The symmetrical models can be discarded because of the asymmetric character of the profiles. The three models with symmetric stress fields are: $(I)$ a state of general crustal compression, which causes a crustal buckling in the trench area; (2) a state of general crustal tension, which causes the formation of a graben in the trench area; (3) the presence of a body of relatively higher densities underneath the trench, which pulls the trench area downward, due to its isostatic subsidence (a foundering mass). Such a high-density body might have been formed by the formation of high density mineral phases in the upper mantle under the stressconditions of 1 ; or by processes of cooling and magmatic differentiation under the stress-conditions of 2 .

The asymmetric structure of the Japan Trench is typical for all circum-Pacific marginal trenches. Their origin has to be explained as a link in a one-sided directed geodynamic process of greater dimensions. This can be (4): The disappearance of the Pacific crust underneath the marginal landmasses owing to the drag of a convection current in the upper mantle at the Pacific side. This current would pitch downward underneath the continents or island arcs. Its downward flow would cause earthquakes which occur at normal, intermediary and great depths in a zone that dips under the continent at an angle of $32-60^{\circ}$.

This is the model which is favoured by the majority of the contemporaneous adherents to the mechanism of (thermal) convection currents (see Fig.5). It has been pointed out that this model is not conform to the distribution of the earthquake foci, as illustrated by Fig.6. Moreover, if the active part of the process is sought at the Pacific side, the overlying ocean crust should be in a state of compression, so that phenomena of folding or irregular crumbling could be expected. 
of the deformations of the geoid, as ascertained by the course of artificial satellites, bears direct relation to the youngest of these geodynamic process only.

Fig. 8 shows clearly that the trends of the Alpine mountain belts have no direct relation with the present-day mega-undations. The Alpine and circum-Pacific ranges result from cycles of mountain-building, which started about 100 to 200 million years ago; consequently they are the result of the earliest phases of the Indian Ocean and Atlantic Mega-undations, which were active at thát time (VAN BEMMELEN, 1964a, 1965a, 1966a). It is obvious that there are no direct connections between the orogenic trend lines established so long ago and the present megaundational gravity anomalies to the geoid. But on closer observation it becomes clear that the youngest northward drift of the Indian shield, and the distortion of the trend lines of the Alpine belt between Afghanistan and Birma (VAN BEMMELEN, 1965a; GANSSER, 1967), as well as the recent seismicity in these areas (BÅTH, 1965) are all closely related to the outlines and gradients of the greatest of all mega-undations of the present time. This active mega-undation represents the third phase in the development of the Indian Ocean Mega-Undation (see Van Bemmelen, 1965a, fig.6, 1967a,b).

It has been suggested that the $A-B-C$ zones are mechanically passive so far as their mega-undatory warping of these outer spheres. Their differential radial movements are caused by a motor situated in the lower mantle. The megaundatory warping of the $A-B-C$ zones leads to a spreading by gravitational flow from the highs towards the lows. Thus continental drift is understood as a phenomenon of gravity flow by means of the potential energy acquired by the crustal entities during the development of mega-undations.

These flow movements tend to obtain the rheological equilibrium. Table II indicates that the isostatic adjustments to mega-undations are almost instantaneous, geologically speaking. The matter of the $A-B-C$ zones cannot support

Legend of Fig.7 (continued from p.101).

Such a prognosis is not confirmed by the diagnostic facts of the reflection profiles (stepfaulting at the Pacific side, shown in Fig.7A). (5) Consequently, only the fifth possibility of the mechanical explanation appears to be adequate. This asymmetric model says that the active movements are coming from the land side, and that the encroaching land masses push the floor of the Pacific ocean downward during their active ("Pacifico-petal") advance over the ocean floor. This model is also in agreement with the seismic refraction section of the Japan trench (see Fig.7B).

B. Seismic refraction section of the Japan Trench along the line $390^{\circ} 45^{\prime} \mathrm{N}$ (After LubwiG et al., 1966, fig.5, p.2126). This asymmetric crustal structure also shows that the symmetric models can be discarded (see caption of Fig.7A, models 1,2 and 3). The choice between the two asymmetric models ( 4 : sea-fioor pushing underneath the land, or 5: landmass spreading over the seafloor) is based primarily on the shallower features, determined by the seismic reflection data (see Fig.7A).

The fifth model, as used for the author's explanation of the mechanism of mega-undations (Fig.4) has mechanical consequences which are confirmed by the data of modern geonomic researches (reflection and refraction seismic profiles, gravimetric profiles, heat-flow data, geological structures). Consequently this model appears to be a functionally adequate working hypothesis. 


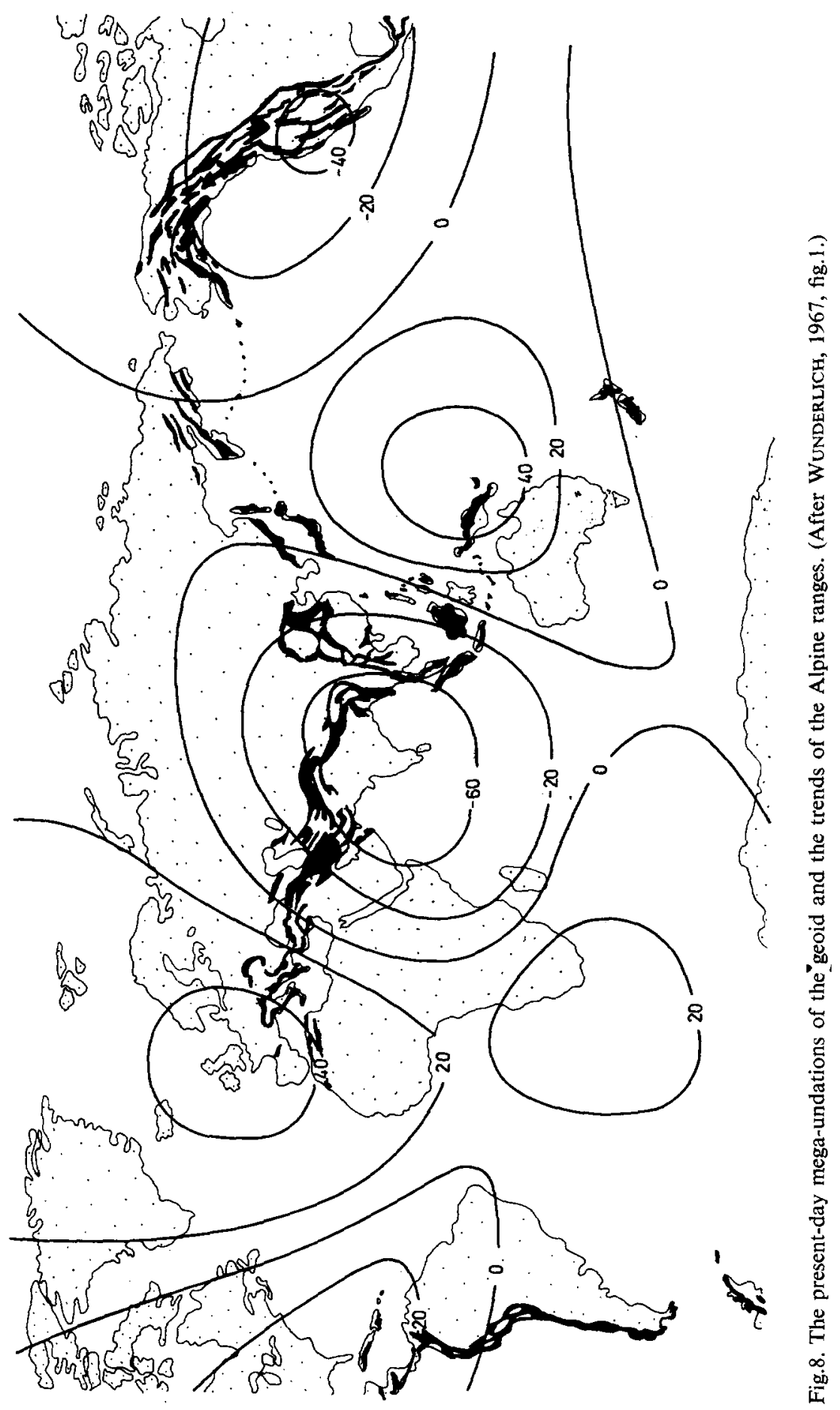

Earth-Sci. Rev., 3 (1967) 79-110 
bulges and downwarps of considerable amplitudes as they are completely wiped out by gravity flow in the course of some thousands of years. But the upward movement of columns in the lower mantle (due to the buoyancy of matter with relatively low density at their base) can proceed during tens of million years, though the position of the crests of the upwarps may shift in the course of time. The mega-undatory fields of gravity anomalies, which are observed by means of artificial satellites, are merely the residual gravity anomaly of active processes of uplift and concomittant spreading.

Apart from this mechanism of passive reaction by gravity flow the introduction of endogenic energy into the outer "Stockwerke" also exerts physicochemical effects in the $A-B-C$ zones. Reduction of confining pressure underneath the new ocean basins causes segregation of a basaltic eutectic fraction at the crest of the mega-undations. This basalt magma may produce the geo-undatory asthenolith underneath the mid-ocean rises and also flood basaltic volcanism at sea and on land. On the other hand, an increase of confining pressure in the areas of mega-undatory subsidence (owing to the encroaching and piling up of glide planks in the $A-B-C$ zones) will promote the formation of high-density mineral phases. The isostatic downward pull of these denser phases brings about the geosynclinal subsidence of the frontal margins of the drifting shields. After an incubation period of about one hundred million years the matter of the subsiding column underneath such frontal geosynclines will have been heated up to the normal temperatures reigning at the depths to which it sank. Consequently, also in this subsiding column of upper mantle matter a tendency towards the segregation of a eutectic basalt fraction will develop in the course of time. This late eugeosynclinal, ophiolitic type of basalt magma is segregated by a rise in temperature, in contrast to the flood basalt (plateau basalt) magma which results from a decrease of pressure in a rising column of upper mantle matter. The eugeosynclinal basaltmagmas will ascend until they reach the sialic crust, which has a lower density and therefore will be initially migmatized and corroded at its base. Ophiolitic suites also finally reach the floor of the geosyncline. This ophiolitic magmatism marks the end of the phase of eugeosynclinal subsidence and starts the phases of mountain building.

The process of oceanization of the Mediterranean type is part of the physico-chemical reactions to the upward and outward flow of endogenic energy. The transmittance of energy from depth to the crust is not a simple transfer of heat by thermal convection currents. It is a highly complicated chain-reaction with intercalated phases of apparent quietude, when the potential energy is temporarily stored as physico-chemical energy. It is the interaction between the physico-chemical forces which are active at a submicroscopic scale and the gravitational forces, acting at a megascopic scale (see Table I). A tentative model of this chain-reaction of the geological evolution has been published as table IV in the author's paper on the present state of the undation theory (VAN BEMMELEN, 1964b). 


\section{CONCLUDING REMARKS}

The foregoging analysis of the importance of the parameters in geonomy points a way to undo the Gordian knot of controversies and antinomies, which at present exist between the static (fixistic) and dynamic (mobilistic) theories on the geological evolution.

The fixists, on the one hand, are right in stating that the earth shows primarily differential radial movements. These deformations of the solid earth are divided by the present author into five classes of undations according to diameter and amplitude. As the diameter of the undation becomes greater, the depth of the causative mass displacements increases ( $C$ and $B$ on Fig.9).

The mobilists, on the other hand, are right in stating that crustal units of continental size can move at the earth's surface with respect to the adjacent crustal units. The present author is of the opinion that all lateral movements are secondary tectonic phenomena of gravitational character; they are due to the potential energy which accumulated in the outer spheres or "Stockwerke" during primary radial (undatory) movements. The greatest class of undations, the megaundations, give rise to the greatest phenomenon of lateral movements, the drift of continental shields. The smallest class of undations, the local diapirs, merely

A

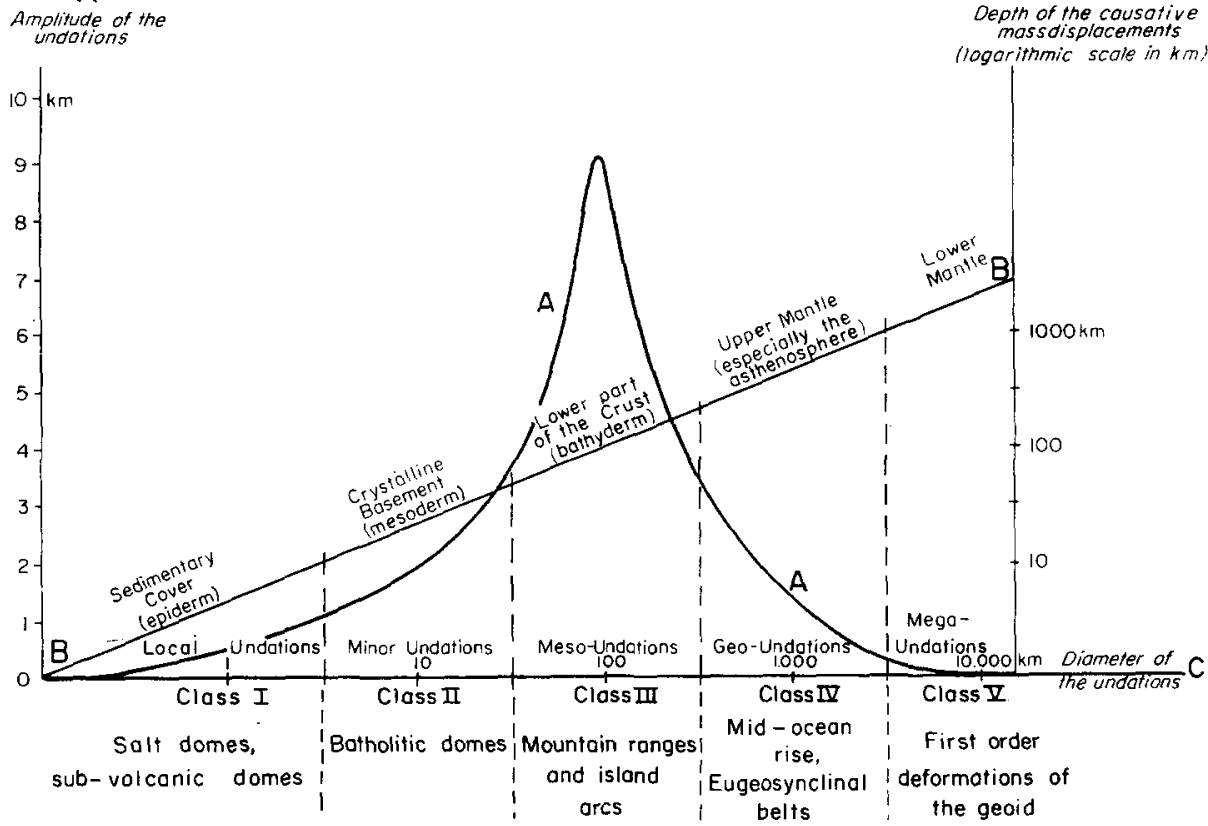

Fig.9. The amplitudes $(A)$ and the diameter $(C)$ of undations in relation with the depth of the causative mass circuits $(B)$. 


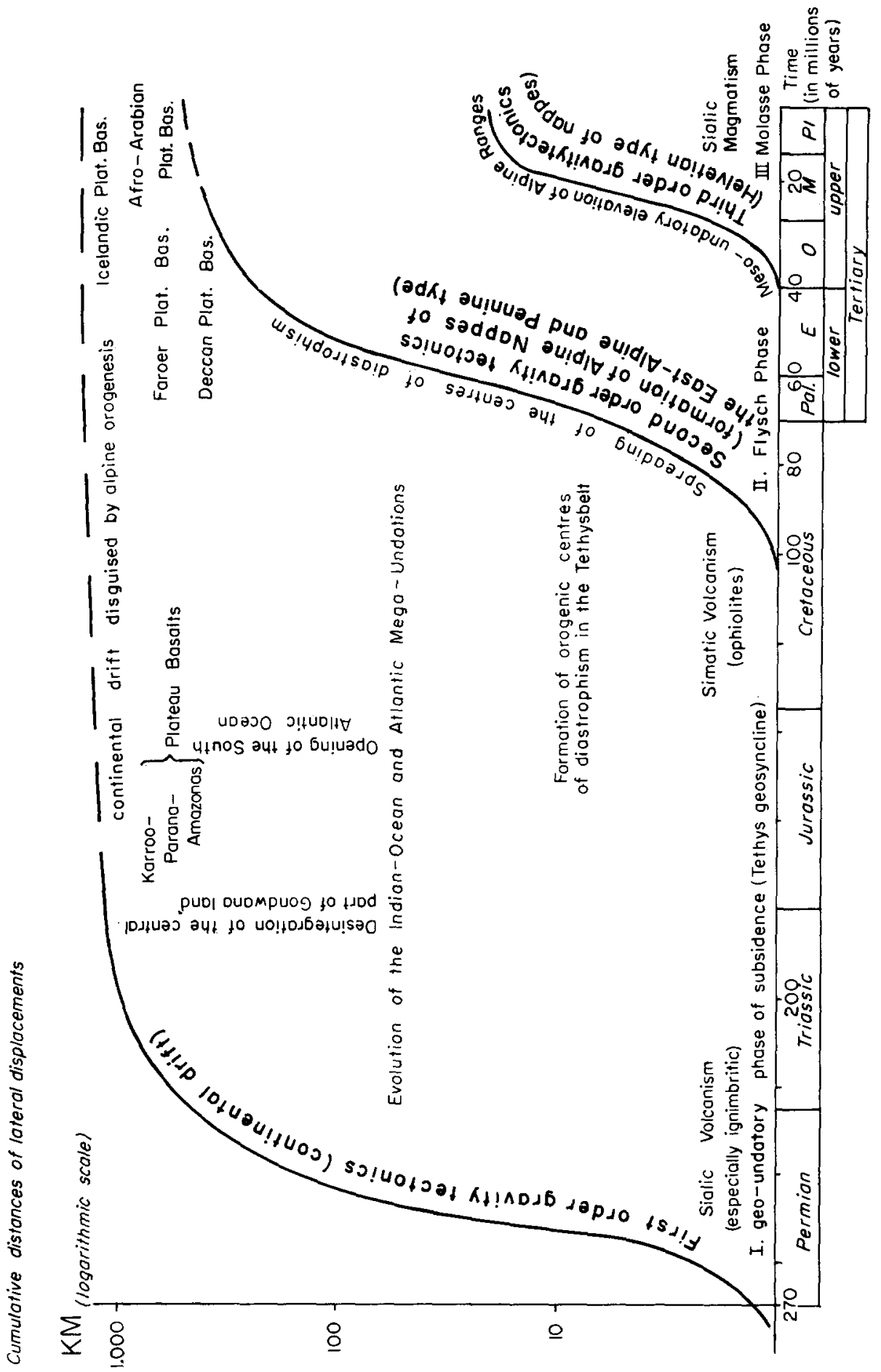

Earth-Sci. Rev., 3 (1967) 79-110 
bring about a mushrooming in their top part and gravitational spreading of their sedimentary roof. In other words, all sideward tectonic movements have primarily a gravitational character (this is the principle of gravitytectonics sensu lato).

Physico-chemical and geodynamic chain-reactions in the mantle determine the evolution of the crust. A deep source of energy produces in the latter cumulative effects of metamorphism, transformism, plutonism, volcanism, and tectonics. As an example of the cumulative effects of the endogenic energy we can mention the European Alps (Fig.10). This mountain range is the result of an orogenic cycle which started about 270 million years ago with a phase of geosynclinal subsidence in the Tethys Belt. The concepts outlined in this paper interpret this slow isostatic subsidence as the effect of the initial phases of evolution of the Indian Ocean Mega-Undation with its indico-fugal spreading of cratonic fragments of the Gondwana continent. Compressive circumstances at the front of the shields produced mineral phases of higher density in the $A-B-C$ zone. This resulted in a slow isostatic subsidence. Thereafter, the chain of reactions engendered in the upper mantle by this first-order process of gravity tectonics has lead, after an incubation period of more than 100 million years, to the formation of orogenic centres of diastrophism in the Tethys Belt. These were upwelling centres of basaltic magma (ophiolitic suite) which caused concomitant spreading of the overlying crustal and sedimentary columns (second-order gravity tectonics of the Flysch phase in Late Mesozoic to Early Cenozoic time).

These spreading movements produced nappes of the east Alpine and Pennine type, which locally may have at their fronts an effect of crustal shortening amounting to hundreds of kilometers. Such regional tectonic processes are superimposed on the more worldwide processes of continental drift. The latter were probably still proceeding during this Flysch phase, but they are disguised by the greater (though more local) movements of overthrusting. It appears that as soon as the tectonic movements of the Flysch phase came to a rest, movements of continental drift dimensions, accompanied by strike-slip sutures, again came to the fore. This intermediate phase of strike-slip movements has been recognized in the Alps by Van Bemmelen and Meulenkamp (1965).

Finally, a third phase of the orogenic drama causes the uplift of the Alpine ranges. This is the Molasse phase, which is accompanied by third-order phenomena of gravity tectonics, such as the décollement of the sedimentary cover and the formation of nappes of the Helvetian type (tectonic denudation). During all these structural phases also various magmatic and metamorphic processes occurred. The initial eugeosynclinal ended with ophiolitic magmatism as the result of basaltic magma, segregated from the upper mantle. This magma could ascend to

Fig.10. Various classes of gravity tectonics during the Alpine cycle of orogenesis according to the principe of relativistic structural analyses. 
the base of the crust or-if penetrating the crust along faults-it eventually reached the floor of the geosynclinal sea. The Molasse phase is accompanied by a more acid magmatism, with the emplacement of tonalitic plutons and volcanism of a hybrid, so-called syntectic composition.

These tectonic and magmatic sequences can all be interpreted as the interrelated effects of the outward flow of endogenic energy by means of the concept of the undation theory, which aims at giving a relativistic synthesis of the fixistic and mobilistic theories of our time.

\section{ACKNOWLEDGEMENTS}

The author would like to thank E. G. Ehlers, C. P. M. Frijlinck, and D. van Hilten for critically reading the manuscript. The opinions expressed in this paper are of course entirely the responsibility of the author.

\section{REFERENCES}

Beloussov, V.V., 1966. Modern concepts of the structure and developments of the earth's crust and the upper mantle of continents. Quart. J. Geol. Soc. London, 122: 293-314.

Beloussov, V. V., 1967. Against continental drift. Sci. J., 1967 (January): 7 pp.

Beloussov, V. V. and RudiTCH, E. M., 1961. Island arcs in the development of the earth's structure (especially in the region of Japan and the sea of Okhotsk). J. Geol., 69: 647-658.

Bernal, J. D., 1961. Continental and oceanic differentiation. Nature, 192: 123-125.

Blacket, P. M. S., Bullard, E. and RunCorn, S. K. (Editors), 1965. A Symposium on Continental Drift-Phil. Trans. Roy. Soc. London, Ser. A, 258: 323 pp.

Bullen, K, E., 1959. An Introduction to the Theory of Seismology. Cambridge Univ. Press, London, $380 \mathrm{pp}$.

Bullen, K. E. and HAdDON, R. A. W., 1967. Earth oscillations and the earth's interior. Nature, 213: 574-576.

CоOK, K. L., 1962. The problem of the mantle-crust mix: lateral inhomogeneity in the uppermost part of the earth's mantle. Advan. Geophys., 9: 295-360.

DE Booy, T., 1966. Neue Daten für die Annahme einer sialischen Kruste unter den frühgeosynklinalen Sedimenten der Tethys. Geol. Rundschau, 56: 94-102.

Den TeX, E., 1965. Metamorphic lineages of orogenic plutonism. Geol. Mijnbouw, 44: 105-132.

Dietz, R. S., 1961. Astroblemes. Sci. Am., 205: 51-58,

Dirac, P. A. M., 1938. A new basis for cosmology. Proc. Roy. Soc. London, Ser. A, 165: 199-208.

GANSSER, A., 1967. The Indian Ocean and the Himalayas. A geological interpretation. Eclogae Geol. Helv., 59: 831-848.

Garland, G. D. (Editor), 1966. Continental Drift. Toronto Univ. Press, Toronto, Ont., $140 \mathrm{pp.}$

Gregor, C. B., 1967. The Geochemical Behaviour of Soda (with Special Reference to post-Algonkian Sedimentation). Thesis, Univ. Utrecht, $66 \mathrm{pp}$.

Harrington, H. J., 1963. Deep focus earthquakes in South America and their possible relation to continental drift. In: A. C. MunYan (Editor), Polar Wandering and Continental DriftSoc. Econ. Paleontologists Mineralogists, Spec. Publ., 10: 55-73.

Holmes, A., 1964. Principles of Physical Geology, 2nd ed. Nelson, London, 1288 pp.

KNOPOFF, L., 1964. The convection current hypothesis. Rev. Geophys., 2: 89-122. 
Ludwig, W. J., Ewing, J. I., Ewing, M., Murauchi, S., Den, N., Asano, S., Hotta, H., HayaKawa, M., Asanuma, T., Ichikawa, K. and NoGuchi, I., 1966. Sediments and structure of the Japan Trench. J. Geophys. Res., 71:2121-2137.

Lustich, Y. N., 1962. Hypothesis of differentiation of the earth's crust and some geotectonic generalizations. Intern. Geol. Rev., 4: 1307-1336.

Neuhaus, A., 1967. Über Phasen und Materiezuständen in den tieferen und tiefsten Erdzonen. Geol. Rundschau, in press.

Nieuwenkamp, W., 1966. Geschichtliche Entwicklung der heutigen petrogenetischen Vorstellungen. Geol. Rundschau, 55: 460-478.

OrowaN, E., 1965. Convection in a non-Newtonian mantle, continental drift, and mountain building. In: P. M. S. BLACKeTt, E. Bullard and S. K. RunCoRn (Editors), A Symposium on Continental Drift-Phil. Trans. Roy. Soc. London, Ser. A, 258: 284-313.

RinGwood, A. E., 1967. New light on the earth's interior. New Scientist, 33: 530-532.

Ringwood, A. E. and GreeN, D. H., 1966. An experimental investigation of the gabbro-eclogite transformation and some geophysical implications. Tectonophysics, 3: 375-382.

Ritsema, A. R., 1964. Some reliable faultplane solutions. Pure Appl. Geophys., 59: 58-74.

RoD, E., 1967. Clues to ancient australian geosutures. Eclogae Geol. Helv., 59: 849-884.

RunCoRN, S. K., 1962. Paleomagnetic evidence for continental drift and its geophysical cause. Intern. Geophys. Ser., 3:1-40.

SCHмIDT, W., 1932. Tektonik und Verformungslehre. Borntraeger, Berlin, 208 pp.

SChuiling, R. D., 1966. Continental drift and oceanic heat-flow. Nature, 210; 1027-1028.

Selli, R., Trevisan, L., Carloni, G. L., Mazzanti, R. and Ciabatti, M., 1965. La frana del Vaiont. Giorn. Geol., 32: 154 pp.

Semenenko, N. P., et al., 1967. Deep crustal structure in Ukrainian crystalline shield. Intern. Geol. Rev., 9: 49-58.

Semenza, E., 1965. Sintesi degli studi geologici sulla frana del Vaiont dal 1959 al 1964. Mem. Museo Trid. Sci. Nat., 16: 51 pp.

Subbotin, S. I., Naumchik, G. L. and Rakhimova, I. S., 1965. Structure of the earth's crust and mantle. Processes in the upper mantle. Influence of upper mantle processes on the structure of the earth's crust. Tectonophysics, 2: 111-209.

Talwani, M., LePichon, X. and Ewing, M., 1965. Crustal structure of the mid-ocean ridges, 2. Computed model from gravity and seismic refraction data. J. Geophys. Res., 70: 341-352.

Tozer, D. C., 1965. Heat transfer and convection currents. In: P. M. S. BLAcketT, E. Bullard and S. K. Runcorn (Editors), A Symposium on Continental Drift--Phil. Trans. Roy. Soc. London, Ser. A, 258: 252-271.

VAN Bemmelen, R. W., 1958. Stromingsstelsels in de silicaatmantel. Geol. Mijnbouw, 20: 1-17.

VAN Bemmelen, R. W., 1962. Geotektonische Stockwerke (Eine relativistische Hypothese der Geotektonik). Mitt. Geol. Ges. Wien, 55: 209-232.

Van Bemmelen, R. W., 1964. The evolution of the Atlantic Mega-Undation. Tectonophysics, 1: 385-430.

Van Bemmelen, R. W., 1964b. Der gegenwärtige Stand der Undationstheorie. Mitt. Geol. Ges. Wien, 57: 379-399.

Van Bemmelen, R. W., 1965a. The evolution of the Indian Ocean Mega-Undation. Tectonophysics, 2: $29-57$.

VAn Bemmelen, R. W., 1966a. On mega-undations: A new model for the earth's evolution. Tectonophysics, 3: 83-127.

Van Bemmelen, R. W., 1966b. Mega-Undationen als Ursache der Kontinentverschiebungen. Mitt. Geol. Ges. Wien, 58: 219-231.

Van Bemmelen, R. W., 1966c. The structural evolution of the Southern Alps. Geol. Mijnbouw, 45: 405-444.

VAN Bemmelen, R. W., 1967a. On the interpretation of the apparent form of the geoid and of the terrestrial heat flow (discussion). Tectonophysics, 4(1): 101-106.

Van Bemmelen, R. W., 1967b. Die Bedeutung der Dimensionen von Länge, Zeit, Druck und Temperatur in der Erdkunde. Geologie, in press. 
Van Bemmelen, R. W. und Meulenkamp, J., 1965. Beitrag zur Geologie des Drauzuges. III. Die Lienzer Dolomiten und ihre geodynamische Bedeutung für die Ostalpen. $\mathrm{Jb}$. Geol. Bundesanstalt, 108: 213-268.

Van Bemmelen, R. W., Berlage, H. P. and Nieuwenkamp, W., 1967. On the origin and evolution of the moon and the crust of the earth. Kon. Ned. Akad. Wetenschap, Proc., in press.

Vening Meinesz, F. A., 1964. The Earth's Crust and Mantle. Elsevier, Amsterdam, 124 pp.

Verfoogen, J., 1965. Phase changes and convection in the earth's mantle. In: P. M. S. BLACKETT, E. Bullard and S. K. Runcorn (Editors), A Symposium on Continental Drift-Phil. Trans. Roy. Soc. London, Ser, A, 258:276-283.

WeGmanN, E., 1956. Stockwerktektonik und Modelle von Gesteinsdifferentiation. Geotekton. Symp. Ehren Hans Stille, 3-19.

WILson, J. T., 1963. Hypothesis of earth's behaviour. Nature, 198: 925-929.

Wunderlich, H. G., 1967. Zur Deutung der Geoid- und Wärmeflussanomalien der Erde: eine Antwort. Tectonophysics, 4: 107-115.

(Received June 4, 1967) 